\title{
Regional Features and Spatial Distribution of Fifty-Eight Ethnic Groups in Southwest China
}

\author{
Yuan Shen ${ }^{1,2}{ }^{\mathbb{D}}$, Danyin Wang ${ }^{3}$, Jiahui $\mathrm{Wu}^{4,5}$, Tianshu $\mathrm{Yu}^{4}$, Tao $\mathrm{Li}^{4,5, *}$ and Siyuan $\mathrm{Li}^{6}$ \\ 1 Suzhou Academy of Agricultural Sciences, Institute of Agricultural Sciences in Taihu Lake Region of Jiangsu, \\ Suzhou 215105, China; ruier55@126.com \\ 2 National Agricultural Experiment Station for Soil Quality, Xiangcheng, Suzhou 215155, China \\ 3 China Population and Development Research Center, Beijing 100081, China; danyin_wang@163.com \\ 4 State Key Laboratory of Urban and Regional Ecology, Research Center for Eco-Environmental Sciences, \\ Chinese Academy of Sciences, Beijing 100085, China; jhwu_st@rcees.ac.cn (J.W.); tsyu@rcees.ac.cn (T.Y.) \\ 5 University of Chinese Academy of Sciences, Beijing 100049, China \\ 6 Zhejiang Development \& Planning Institute, Hangzhou 310030, China; syli11@163.com \\ * Correspondence: taoli_st@rcees.ac.cn; Tel.: +86-10-6284-9112
}

Citation: Shen, Y.; Wang, D.; Wu, J.; Yu, T.; Li, T.; Li, S. Regional Features and Spatial Distribution of Fifty-Eight Ethnic Groups in Southwest China. Sustainability 2021, 13, 13570. https://doi.org/10.3390/su132413570

Academic Editor: Colin Michael Hall

Received: 15 November 2021

Accepted: 7 December 2021

Published: 8 December 2021

Publisher's Note: MDPI stays neutral with regard to jurisdictional claims in published maps and institutional affiliations.

Copyright: $\odot 2021$ by the authors. Licensee MDPI, Basel, Switzerland. This article is an open access article distributed under the terms and conditions of the Creative Commons Attribution (CC BY) license (https:// creativecommons.org/licenses/by/ $4.0 /)$.

\begin{abstract}
Eco-environmental variability was the basis of ethnic diversity with a persistent influence on the regional development. The unique geographic conditions and multi-ethnic characteristics in southwest China were valuable for exploring sustainable development of ethnic regions. In this study, the regional features of distribution areas of ethnic groups in southwest China were analysed, and it was found that average altitude, slope, water coverage and water form ratio of each ethnic group differed apparently. Additionally, regional features of southern minorities were relatively stable, while those of northern minorities changed evidently from 1990 to 2010. Furthermore, taking the spatial coordinates and regional features as parameters, fifty-eight ethnic groups were clustered into six categories via spatial cluster analysis. Moreover, based on the county-level population data, the ethnic similarities in southwest China were identified by correlation analysis, and the results were in accordance with those of spatial cluster analysis but more detailed. In addition, the ecoenvironmental adaptability of various ethnic groups was discussed in terms of living and production as well as regional sustainable development. This research was of referential meaning for population settlement, natural resources utilization and biodiversity conservation in multi-ethnic regions.
\end{abstract}

Keywords: geographical variety; eco-environmental adaptability; ethnic diversity; spatial cluster analysis; correlation analysis; regional sustainability; southwest China

\section{Introduction}

Ecological environment has great importance in understanding the diverse regional development processes, which could not only be observed via international cultural and economic exchanges $[1,2]$ but could also be embodied by regional competition and cooperation within countries [3,4]. The technological innovation and political-economic change over the years have promoted the adaptation of mankind to eco-environmental variability in some degree $[5,6]$. However, because the social and economic disparities caused by natural variability have existed for a long time, the historical process and geographical pattern persisted affecting the population distribution. This persistence was performed as the phenomenon that the regional ecological environment usually constrained human migration, especially those who tried to change themselves but found it difficult to overcome challenges in their new environment [7]. In order to adapt to the unfamiliar environment of the certain region, the difficulties they faced were even physiological obstacles in addition to a variety of cognitive behaviours [8].

Geographic location and conditions determined the spatial distribution and availability of natural resources [9]. The population residing in a particular region generated 
a corresponding way of living and production that adjusted to the local ecological environment so that the style and degree of resources utilization of different populations might be divergent [10]. Furthermore, it was proved that natural resources decreased income inequality in ethnically homogeneous societies while increasing that in ethnically polarized societies [11]. It meant that the spatial disparities of natural resources caused by eco-environmental factors affected the living standards of diverse populations. Thus, when the regional ecological environment changed, or the population expanded, people would migrate to find the appropriate new settlement. In the long course of history, assimilation and aggregation, along with differentiation and isolation among populations, came into being, and the ecological and social interactions that have taken place between the populations and the environment formed certain relationships gradually during their long-term evolutionary process.

China is a multi-ethnic country. As the ecological environment, climate conditions and production materials differed in their habitats, various ethnic groups gradually formed distinct and colourful ethnic cultures in their historical evolution [12]. There were 55 ethnic minorities in China, with the population accounting for $8.5 \%$ of the total, scattered over $64.2 \%$ of the national territory area [13]. Most ethnic minorities had their own language, and people belonging to a particular ethnic minority often shared common historical and religious beliefs [14]. Southwest China was a unique region with multiple landforms, including the coastal plain, basin, hills, mountain land and plateau. On account of the largest number of ethnic minorities, population of the thirty-four native ethnic minorities in southwest China was about 54.13 million in 2010, accounting for $48.3 \%$ of the total population of ethnic minorities in China. Owing to the distinguished eco-environmental features and multi-ethnic traditions, the richness of both nature and culture in southwest China was of great value to probe into the spatial distribution of the ethnic population on a large scale, which was beneficial to sustainable development of ethnic regions [15].

Some literature has confirmed that eco-environmental variability was the basis of ethnic diversity and had a persistent impact $[7,16,17]$. Nevertheless, current research lacked empirical studies at large scale on long time series, and the reports on geographical characteristics and regional sustainability from the perspective of ethnic population were insufficient. In this study, we specifically aimed to provide a method for identifying regional features and spatial distribution based on ethnic groups at a large spatial-temporal scale. Therefore, the spatial coordinates and regional features of distribution areas of ethnic groups were analysed, and then the spatial cluster analysis of ethnic groups was carried out. Meanwhile, correlation analysis of ethnic groups was conducted based on the county-level population data of southwest China. Finally, this study discussed the effect of regional ecological environment on ethnic population distribution as well as the relationship between living and production of different ethnic groups and regional sustainable development.

\section{Data and Methods}

\subsection{Study Area}

Under the background of natural divisions, the geographical range of southwest China mainly includes various topographic units such as the southern part of QinghaiTibet Plateau, the Sichuan Basin, the Yunnan-Guizhou Plateau and the western part of hilly areas in Guangdong and Guangxi [18]. In this study, the administrative region of southwest China refers to Guangxi Zhuang Autonomous Region, Chongqing Municipality, Sichuan Province, Guizhou Province and Yunnan Province, as well as Lhasa, Nagqu, Lhoka, Nyingchi, Qamdo Prefectures of Tibet Autonomous Region and Yushu Tibetan Autonomous Prefecture of Qinghai Province (including Tanggula Town, the enclave of Geermu City). Across $85^{\circ} 3^{\prime} \mathrm{E}-112^{\circ} 3^{\prime} \mathrm{E}, 20^{\circ} 54^{\prime} \mathrm{N}-36^{\circ} 29^{\prime} \mathrm{N}$, southwest China is a region with a total area of $230,200 \mathrm{~km}^{2}$, accounting for $23.9 \%$ of the national territory area. Except for the Sichuan Basin and the coastal plain of Guangxi, the elevation of southwest China is 
more than $1000 \mathrm{~m}$ above sea level, especially the Qinghai-Tibet Plateau at even more than $4000 \mathrm{~m}$ (Figure 1).

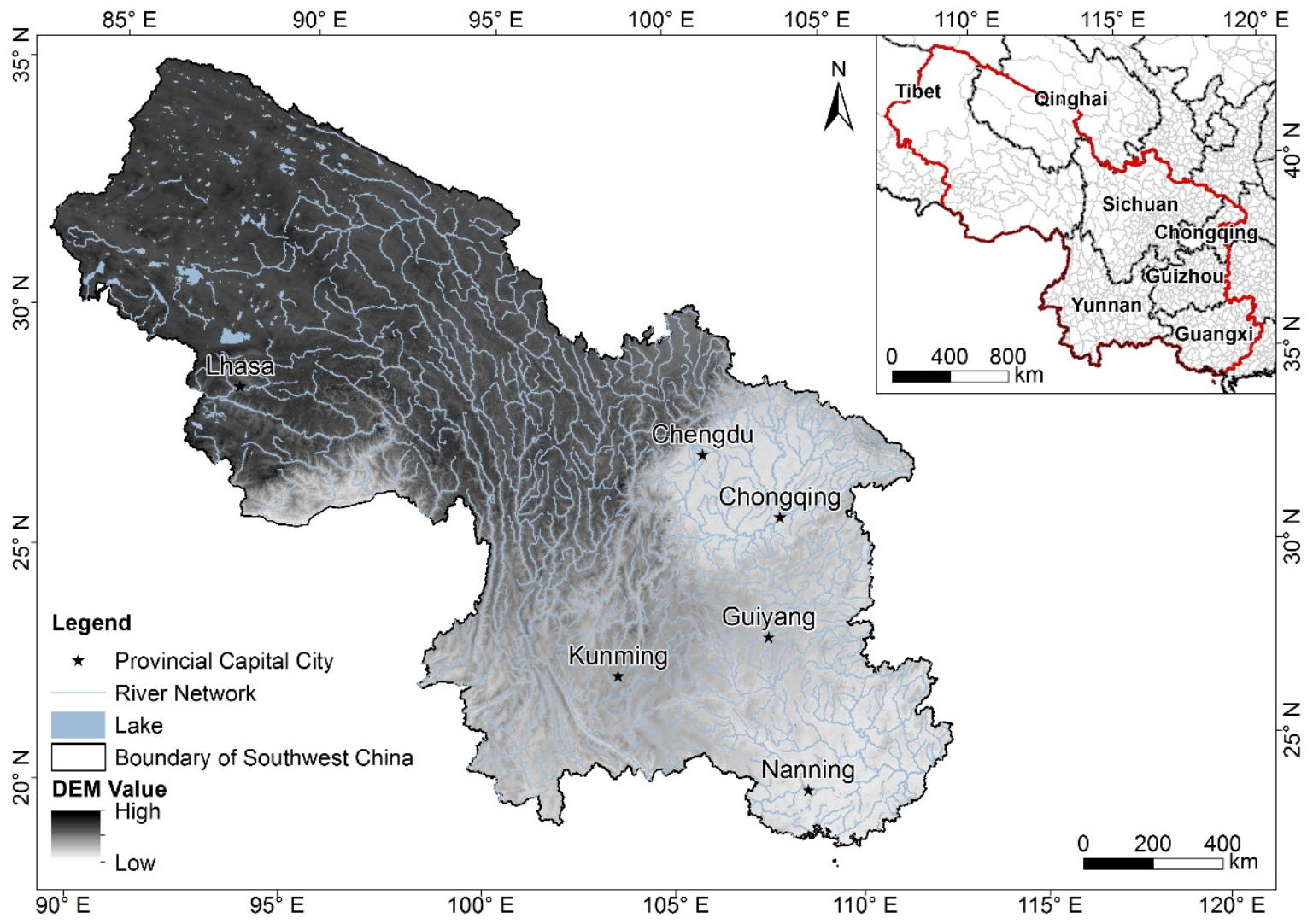

Figure 1. Location of southwest China.

\subsection{Data Source}

The vector data of administrative division boundary and waters as well as the raster data of digital elevation model (DEM, resolution was $30 \mathrm{~m}$ ) were obtained from the Institute of Remote Sensing and Digital Earth, Chinese Academy of Sciences. The ethnic population data were derived from the nationwide population censuses as the fourth in 1990 [19], the fifth in 2000 [20] and the sixth in 2010 [21], in which fifty-six ethnicities were recognized by the central government. Added by "unidentified ethnic people" and "foreigners joined Chinese nationality", there were a total of fifty-eight ethnic groups to be taken into consideration. Among them, fifty-five ethnic minorities could be divided into thirty-four southern minorities and twenty-one northern minorities relied on their historical geographical locations [22]. All the English names of the ethnic groups were referred to Encyclopedia of China: Nation [23]. Based on the county-level administrative regions, the total number of research units in 1990, 2000 and 2010 was respectively 582, 598 and 602 , due to local changes in administrative divisions.

\subsection{Research Methods}

The values of spatial coordinate and regional feature for each research unit were calculated. First, this study extracted the geographic coordinate of geometric centre for each research unit according to the vector data of county-level administrative division boundary, based on the geographic coordinate system GCS_WGS_1984 in the ArcGIS version 10.2 software (https://resources.arcgis.com/en/help/main/10.2/index.html, accessed on 15 March 2021). Next, the average altitude, the average slope, water coverage, water perimeter and water area of each research unit was obtained from the DEM and the vector layers of waters using the spatial analysis tool "Slope" and "Zonal". Then, the water 
perimeter was divided by its area of each research unit in order to calculate the ratio of water form. The larger the ratio, the more river-like the waters were, while the smaller the ratio, the more lake-like the waters were. After the above steps, the spatial coordinates and regional features including altitude, slope, water coverage and water form ratio for all the research units in 1990, 2000 and 2010 were achieved respectively. The detailed information of the values could be found at Table S1 online.

The geographic coordinates of population gravity centres of all the ethnic groups in southwest China were figured out by the gravity centre theory. For a region with a number of subregional units, the gravity centre of a particular attribute was usually expressed by this attribute and the geographic coordinates of each subregional units [24]. Given that southwest China is composed of $n$ research units, where the coordinate of geometric centre of the $i$ th research unit is $\left(x_{i}, y_{i}\right)$, and $P_{i j}$ is the population amount of the $j$ th ethnic group in the $i$ th research unit, then the geographic coordinate of population gravity centre $\left(X_{j}, Y_{j}\right)$ of the $j$ th ethnic group is as follows:

$$
X_{j}=\frac{\sum_{i=1}^{n}\left(P_{i j} \cdot x_{i}\right)}{\sum_{i=1}^{n} P_{i j}}, Y_{j}=\frac{\sum_{i=1}^{n}\left(P_{i j} \cdot y_{i}\right)}{\sum_{i=1}^{n} P_{i j}}
$$

Inspired by the idea of gravity centre theory, the average values of regional features for each ethnic group can be calculated based on the population amount and the values of the features of each research unit. As $r_{i k}$ is the value of the $k$ th regional feature in the $i$ th research unit, then the value of the $k$ th regional feature of the $j$ th ethnic group, $R_{j k}$, in southwest China is as follows:

$$
R_{j k}=\frac{\sum_{i=1}^{n}\left(P_{i j} \cdot r_{i k}\right)}{\sum_{i=1}^{n} P_{i j}}
$$

Then taking spatial coordinates and all the regional features as the specific parameters, this study used the cluster analysis tool "Grouping Analysis" in ArcGIS version 10.2 software to cluster the fifty-eight ethnic groups. The principle of cluster analysis was that the regional features of all the members within the same category were as similar as possible to each other, while those between the categories were as different as possible.

Furthermore, based on the population panel data, the Pearson correlation coefficients of the bivariate ethnic groups in 1990, 2000 and 2010 with the two-tailed significance test were calculated by the correlation analysis function in the IBM SPSS Statistics V20.0.0 software (https://www.ibm.com/support/pages/node/429179, accessed on 26 April 2021). As a result, there was $1653\left(C_{58}^{2}\right)$ correlation coefficient values of ethnic group couples each year, using the county-level population data. Subsequently, ethnic group couples that reached highly significant correlations at the 0.01 level in a two-tailed test simultaneously in the three years were selected to determine the inter-relationship among all the ethnic groups, which was plotted afterwards. The precise Pearson correlation coefficients with their actual $p$ values in 1990, 2000 and 2010 could be seen respectively in Tables S2-S4 online.

\section{Results}

\subsection{Spatial Cluster Analysis}

The regional features of distribution areas of various ethnic groups in southwest China were distinct, and the detailed values could be found at Table S1 online. In terms of topography, the average altitudes and slopes of distribution areas of the total population were lower than the geographic average values in southwest China, tending to lower altitude and gentler slope from 1990 to 2010. The altitude changes of distribution areas of northern minorities over time were relatively large, reflecting the process of seeking their suitable settlements during population growth and migration. At the same time, the average slopes of distribution areas of some northern minorities, such as Bonan, Kazak, Uzbek, Tatar, Uygur and Daur, increased obviously because they endeavoured to adapt to the different topographic conditions for expanding their distribution areas. As southern 
minorities have inhabited southwest China for a long time, each of them distributed at a certain altitude from $200 \mathrm{~m}$ to $3000 \mathrm{~m}$, with a slight change over time. Besides, the average slopes of distribution areas of many southern minorities, such as $\mathrm{Nu}$, Derung, Monba, Lhoba, Qiang and so on, were at the forefront, showing the adaptation of indigenous people to topography in full. As for water resources, the average water coverage of the total population was close to the geographic average value in southwest China, which indicated that people's demand for water resources was consistent with the spatial distribution of water resources. When it turned to temporal change, most ethnic groups were inclined to the region with more abundant water. Via the calculation and analysis of water form ratios, it was found that the water form ratios of distribution areas of the total population increased from 1990 to 2010, namely, most people tended to the region with more river-like waters over time. On top of that, most population in southwest China was distributed in the areas with more lake-like waters, while most ethnic minorities adapted to the region with river-like waters nearby.

Taking the spatial coordinates and regional features as the specific parameters, fiftyeight ethnic groups were clustered into six categories. As shown in Figure 2, the three years were represented by different shapes of population gravity centres of fifty-eight ethnic groups, and the six categories were symbolized by diverse colours. Regional features of groups within the same category were as similar as possible but were different from other categories.

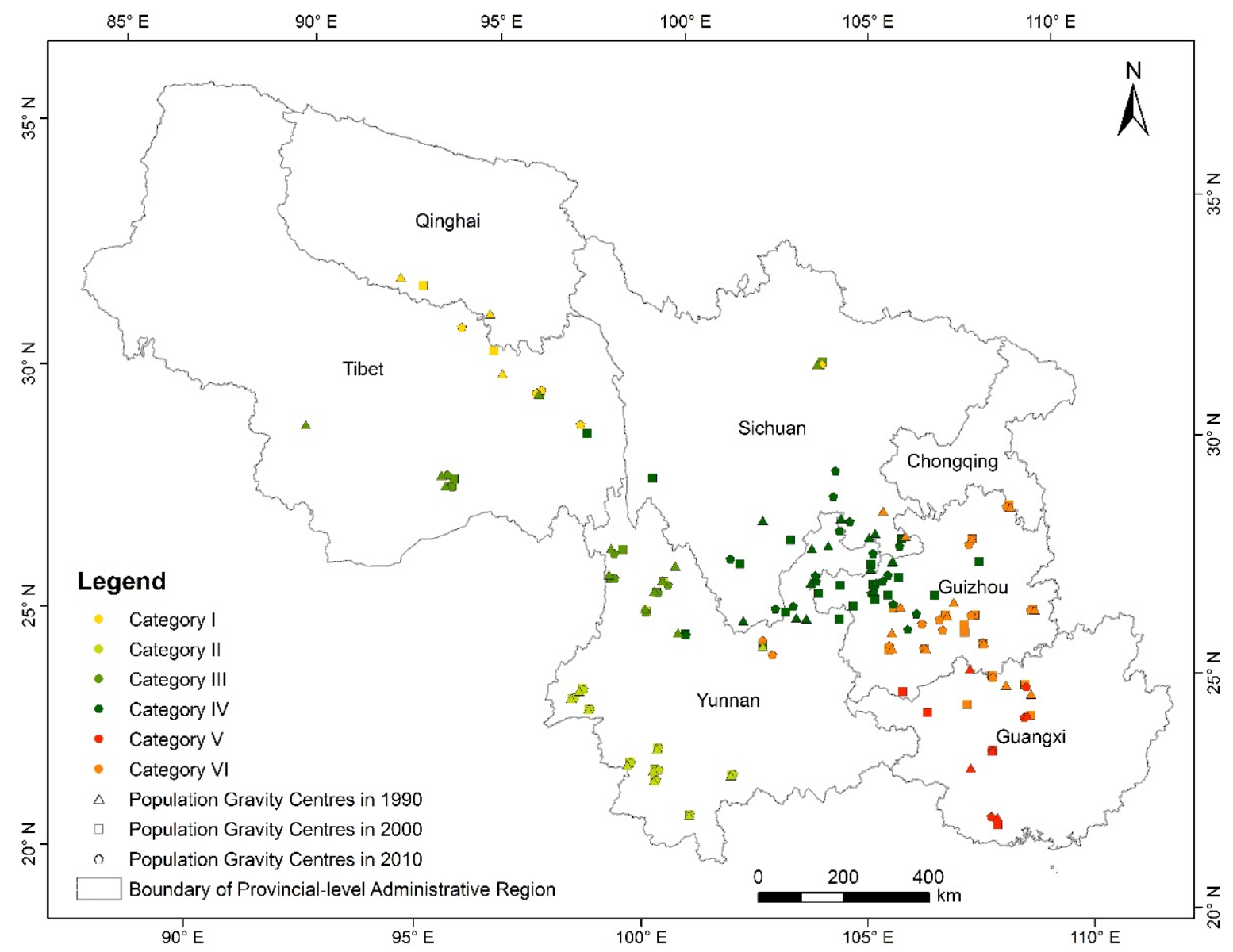

Figure 2. Spatial cluster distribution of ethnic groups in southwest China.

All the outcomes of spatial cluster analysis were beneficial to identify the similarities and differences of regional features and spatial distribution among all the ethnic groups, thus embodying the proximity or alienation of the fifty-eight ethnic groups in geography. 
- Category I consisted of northern minorities, such as Salar, Dongxiang, Bonan, Kazak and so on, which were mostly distributed in the Qinghai-Tibet Plateau. Obviously, movement distance of population gravity centres of Category I was large from 1990 to 2010 as they were looking for appropriate settlements. Due to their regional features, the average altitudes of distribution areas of the members in Category I were all higher than $3000 \mathrm{~m}$, which was generally the highest among the six categories. Meanwhile, their water form ratios were low, indicating that these northern minorities in migration tended to live near river-like waters.

- Category II was mainly located around the southwest border of Yunnan, consisting of nine southern minorities, namely, Achang, Jingpo, De'ang, Dai, Va, Blang, Lahu, Jino and Hani. The average altitudes of their distribution areas were about $1400 \mathrm{~m}$, and the average slopes were at the range of $16^{\circ}$ to $21^{\circ}$. It was worth mentioning that the water coverages of distribution areas of the members in Category II were less than $0.3 \%$, which was the smallest among the six categories.

- Lhoba, Menba and Tibetan in southeast Tibet, and Qiang in northern Sichuan, as well as the Derung, Nu, Naxi, Primi, Lisu and Bai in Hengduan Mountains constituted Category III. The average altitudes of their distribution areas were mostly at the range of $2000 \mathrm{~m}$ to $3000 \mathrm{~m}$, while that of Tibetan was more than $4000 \mathrm{~m}$, being the highest among the fifty-eight ethnic groups. Meanwhile, the average slopes of distribution areas of these southern minorities made Category III the largest among the six categories, and that of $\mathrm{Nu}$ was even up to $31^{\circ}$. In addition, their water coverages were also apparently lower than the geographic average value $(1.3 \%)$ in southwest China. The results of regional features of Category II and III demonstrated sufficient adaptation of native southern minorities to high altitudes and mountainous topography, along with their efficient usage of water resources.

- Members of Category IV were northern minorities gathered at the junction of Sichuan, Guizhou and Yunnan, primarily consisting of Russ, Tatar, Kirgiz, Hezhen, Hui, Chaoxian, Man, Mongol, Uygur, Xibe, Ewenki and Daur. The average altitudes of distribution areas of the members in Category IV were about $900 \mathrm{~m}$, and their average slopes made the category the smallest among the six categories, less than $10^{\circ}$. Besides, their water coverages and water form ratios were relatively high, manifesting that the immigrated northern minorities preferred to relocate in the region with lower altitude, gentler slope, rich water resources and lake-like waters nearby.

- Category V included Mulam, Yao, Zhuang and Gin, which were the main southern minorities scattered in the territory of Guangxi. They all distributed in the plain area with average altitudes less than $500 \mathrm{~m}$, and their water form ratios were very low, indicating that these southern minorities settled in the region with plentiful river network.

- $\quad$ Bouyei, Sui, Li, Miao, Tujia, Dong, Gelao, Gaoshan, She and others constituted Category VI spreading over the territory of Guizhou. The average altitudes of their distribution areas were about $1100 \mathrm{~m}$, and their average slopes were slightly lower than the geographic average value $\left(15.93^{\circ}\right)$ in southwest China. In terms of the water resources, their water coverages were low, while their water form ratios were high. The results of regional features of Category V and VI showed the diversity in spatial distribution of southern minorities.

\subsection{Population Correlation Analysis}

Through the analysis of regional features and spatial cluster of all the ethnic groups, it was clear that some ethnic groups had the same preference in the choice of distribution areas, although different ethnic groups had variant demands on geographic conditions. Hence, the correlation analysis of the population data respectively in 1990, 2000 and 2010 would help to find the inter-relationship among the fifty-eight ethnic groups from the perspective of statistical analysis. 
The considerable correlation coefficients demonstrated that certain ethnic group couples were closely related in population distribution. Based on the county-level population data, seventy-five ethnic group couples, out of the total 1653 couples, reached highly significant correlations simultaneously in the 1990, 2000 and 2010, among which seventy were positive while five were negative. Based on that, the inter-relationship between fifty-eight ethnic groups was sorted out and then plotted as shown in Figure 3. Positive correlations were symbolized by the solid lines, while negative correlations were the dotted lines. Ethnic groups inside one rounded rectangle showed their same correlation with each other. Two-tailed tests were used to generate these significant correlations with $p<0.01$, and the Pearson correlation coefficients with their $p$ values could be seen in Tables S2-S4 online.

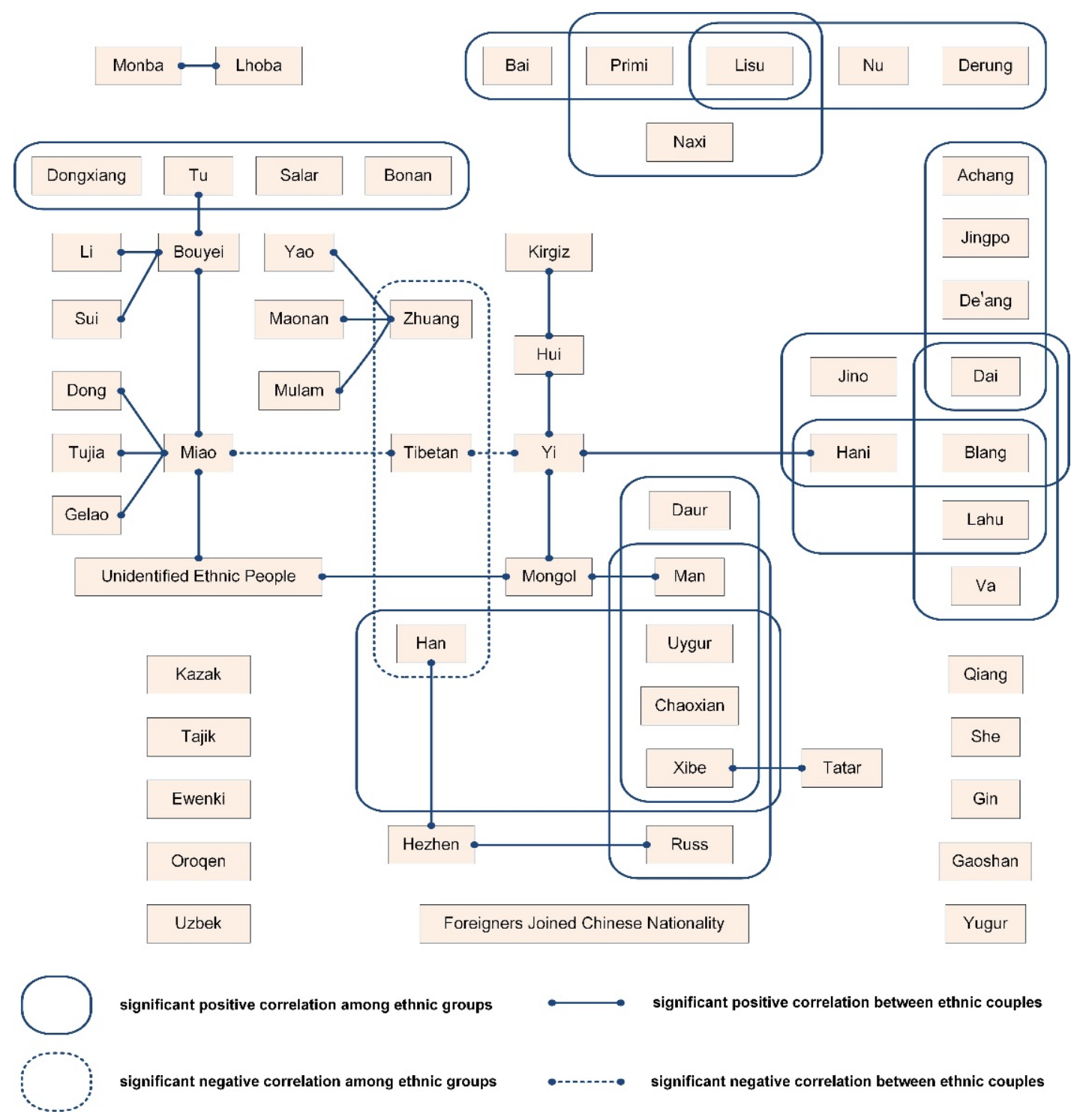

Figure 3. The inter-relationship among the fifty-eight ethnic groups in southwest China.

Dwelling in southeast Tibet, Monba and Lhoba made up a correlative couple, with a positive correlation coefficient of 0.740 , which was independent of other ethnic groups. In other words, their population distribution was highly consistent with each other but was completely different from that of other ethnic groups. Derung, Nu, Naxi, Lisu, Primi and Bai mainly distributed in the Hengduan Mountains represented positive correlations as a category which was independent of other ethnic groups. Besides, four northern minorities of Dongxiang, Tu, Salar and Bonan formed a category with positive correlations. 
In addition, there was a significant negative correlation between any two of Zhuang, Tibetan and Han, meaning the mutual exclusion of each other. Additionally, Tibetan also held a negative correlation with Miao or Yi. This indicated that the population of Zhuang, Han, Miao or Yi was less settled in the areas suitable for the Tibetan, and vice versa. On top of that, Han and some northern minorities, such as Daur, Man, Uygur, Chaoxian, Xibe, Russ and so on, participated in a category with positive correlations, and so did some southern minorities such as Jingpo, De'ang, Dai, Blang, Lahu, Va, Jino and Hani, primarily populating near the southwest border of Yunnan. Moreover, Bouyei, Miao, Yi and Mongol connected with the above four categories in series and had positive correlations with other specific ethnic groups meanwhile. At last, eleven more ethnic groups were respectively independent in southwest China, with no significant correlations, illustrating that the spatial distribution of these ethnic groups was distinct from others.

The results of correlation analysis confirmed those of spatial cluster analysis and further enriched the inter-relationship among fifty-eight ethnic groups in southwest China. By comparing these results, it can be drawn that all the eight southern minorities at the top of Figure 3 were members of Category III in Figure 2. Dongxiang, Tu, Salar and Bonan formed the main part of Category I. A number of southern minorities at the left side gathered to become Category VI. Some southern minorities, taking Zhuang as the core, represented Category V. Northern minorities at the middle-bottom of Figure 3 were consistent with the members in Category IV. The nine southern minorities at the right side were the same as the members in Category II. Consequently, through the analysis on the regional features and spatial distribution in southwest China from multi-angles via different methods, this research achieved some reliable results of mutual support.

\section{Discussion}

During the process of origination and development of ethnic groups, both the material culture and spiritual culture along with the customs and mentality exhibited by ethnic categories grew up under the influence of various factors, especially the geographic conditions of their distribution areas [25]. Therefore, eco-environmental adaptability of various ethnic groups could be observed from the aspects of living and production, which was helpful to the sustainable development of the region.

\subsection{Eco-Environmental Adaptability of Ethnic Groups}

Monba, Lhoba and Tibetan were native southern minorities inhabited in Tibet. The high altitude there made the oxygen content in the air only about three-fifths of that in the plain area, so the plateau ethnicities have engendered hypoxia adaptation mechanism in physiology [26]. That is, maladaptive acclimatization response to hypoxia of plateau ancestors received genetic inactivation by generation selection [27]. Moreover, unique topographic features of southeast Tibet affected the lifestyle and culture of local populations, which fundamentally limited the associations of Monba and Lhoba with other ethnic groups beyond the geographic boundaries [28]. Thus, the indigenous people of these two ethnicities formed an independent crowd of close contact. Different from Monba and Lhoba, Tibetan was the dominating ethnic group over the Qinghai-Tibet Plateau due to historical reasons [22,29]. Starting from 2000, Great Development of the West in China has prompted the central government to devote more infrastructure and economic incentives for westward migration, but high altitude was still a huge challenge for the plain population to relocate in Tibet, especially with altitude sickness [7]. Because the physiological disorders generated from natural barriers did not go away, the geographical integration of different ethnic groups would be a gradual process. As shown in our results, the correlations between Tibetan and other related ethnic groups were substantially negative, manifesting the spatial distribution of mutual exclusion.

Rice (Oryza sativa L.) was one of the major food crops for various ethnic groups in southwest China, providing the basic needs for peoples' survival and development [30]. Rice was a thermophilic hygrophyte, with less demand on the soil, but was sensitive to 
changes in temperature and moisture. Thus, hydrothermal conditions and landforms must be considered when choosing the appropriate planting areas for cultivation [31]. Dai, Blang, Lahu, and Hani all populated near the southwest border of Yunnan, and it has been verified that the population proportion of Dai, Hani, Lahu and Blang were closely related to the richness of rice varieties [32]. Tracing the history of ethnic culture and rice cropping culture, Dai's ancestors were found to be the earliest rice cultivators in China. The long history of rice cultivation might contribute to the accumulation of rice varieties in Dai's distribution areas [33]. Regional rotation phenomenon of rice seed was common for Hani, as relatives and friends were used to exchange rice seeds, which would not only help to prevent the rice aging but also preserve the traditional rice germplasm resources [34]. Likewise, Lahu and Blang also had a long history of rice cropping, with religious traditions to conserve the rice varieties, which enriched their diversity of rice varieties to a certain extent $[35,36]$. It could be seen that different ethnic groups resided in a similar ecological environment for the purpose of possessing the production means, whereas diverse cultural background enabled them to produce by separate ways so that all of them coexisted harmoniously.

\subsection{Sustainbale Livelihoods of Ethnic Region}

The living and production of ethnic groups depended on the regional ecological environment and affected the ecological environment at the same time. In general, ethnic minorities in southwest China settled in the areas with high altitude and steep slope, and their early living and production were more dependent on traditional livelihoods including conventional gathering, cultivation, and breeding, which were highly dependent on local resources and environment affected by natural factors such as climate and disasters [37]. These traditional livelihoods could ensure the stability and permanence of the local ecosystem to a certain extent and were of great value to the protection of the regional ecological environment along with the sustainable use of natural resources [38]. Moreover, some ethnic groups have developed a whole set of behaviors including the resource sharing within the group and supporting mechanisms in order to guarantee the resource sustainability, which could ensure their long-term regional livelihood security as well as the sustainable ecological environment [39,40].

Although the unique geographical environment and the early traditional livelihood were beneficial to the sustainability of regional ecological environment, to a large extent, they hindered the sustainable development of regional social economy and the cultural exchange of ethnic groups. Therefore, with the impact of social change and the market economy, ethnic groups tend to migrate to areas with low altitudes and gentle slopes, and their livelihood has changed from the traditional livelihood of farming and animal husbandry to sedentary agriculture, and some other new livelihood ways such as ecological products and cultural tourism [41]. These changes have provided convenience and opportunities for economic development, human welfare and cultural exchanges in ethnic regions. Especially the development of ecological tourism and ethnic tourism oriented by ethnic culture not only improved the regional economic level but also contributed to the wide spread of ethnic culture. As a form of sustainable livelihood with low consumption and high efficiency, ethnic tourism has become an important starting point to accelerate the development of rural and western areas in China. However, excessive exploitation of tourism activities will inevitably increase the human interference to the ecological environment and threaten the regional ecological security. In addition, the over-commercialization of ethnic culture probably resulting in the gradual vanish of agricultural knowledge and collapse of neighboring relationship should be on guard [42] Therefore, the local authorities should reasonably develop ecotourism brands centered on the elements of natural resource, sacred environment and ethnic culture, which could not only promote the sustainable development of regional ecology, society, and economy, but also facilitate the exchange and inheritance of ethnic culture. 


\section{Conclusions}

Our research manifested that the average altitude, slope, water coverage and water form ratio for each ethnic group were distinct. The spatial cluster analysis was taken to obtain six categories, which was conducive to identify their selection preferences for ecological environment. Based on the county-level population data, the correlation analysis of bivariate ethnic groups was conducted, of which the results concerning the inter-relationship among ethnic groups in southwest China echoed those of spatial cluster analysis but more detailed. In general, fifty-eight ethnic groups were divided into five positive correlated categories, one Tibetan-based negative correlated category, several connecting ethnic groups with positive correlations, and eleven independent ethnic groups including four southern minorities.

For the sake of exploring regional features and spatial distribution based on ethnic groups in southwest China, ethnic inter-relationship was identified by both spatial analysis and statistical analysis with reliable results of mutual support. The results indicated that regional ecological environment played an important role in the spatial distribution of ethnic groups, providing an effective way to study the eco-environmental adaptability of ethnic groups in a large scale. Furthermore, a system of regional ethnic autonomy might be another influential factor which would affect the spatial mobility of the population from the perspectives of social governance. Thus, combined with the spatial distribution of autonomous administrative units, the method used in this study could be improved to be more comprehensive in the future. Moreover, it will be necessary to carry out continuous research on the basis of the new census data and fine vector data in order to provide scientific reference for the sustainable development of southwest China.

Supplementary Materials: The following are available online at https: / www.mdpi.com/article / 10.3390/su132413570/s1, Table S1: The spatial coordinates of population gravity centres and the average values of regional features of all the ethnic groups in southwest China, Table S2: Pearson correlation coefficients of the bivariate ethnic groups and their corresponding $p$ values from the bilateral significance test in 1990, Table S3: Pearson correlation coefficients of the bivariate ethnic groups and their corresponding $p$ values from the bilateral significance test in 2000, Table S4: Pearson correlation coefficients of the bivariate ethnic groups and their corresponding $\mathrm{P}$ values from the bilateral significance test in 2010 .

Author Contributions: Conceptualization, Y.S.; Methodology, D.W.; Formal Analysis, J.W.; Data Curation, T.Y.; Validation, T.L.; Software, S.L.; Writing-Original Draft Preparation, Y.S. and D.W.; Writing-Review \& Editing, Y.S., D.W., J.W., T.Y., T.L. and S.L.; Funding Acquisition, T.L.; Supervision, S.L. All authors have read and agreed to the published version of the manuscript.

Funding: This research was funded by the Second Tibetan Plateau Scientific Expedition and Research (grant number 2019QZKK04020104) and the National Key Technologies Research and Developing Program of China (grant number 2016YFC0502106).

Conflicts of Interest: The authors declare no conflict of interest.

\section{References}

1. Falck, O.; Heblich, S.; Lameli, A.; Südekum, J. Dialects, cultural identity, and economic exchange. J. Urban Econ. 2012, 72, 225-239. [CrossRef]

2. Pei, Q.; Zhang, D.D.; Lee, H.F. Contextualizing human migration in different agro-ecological zones in ancient China. Quat. Int. 2016, 426, 65-74. [CrossRef]

3. Castaldi, C.; Los, B. Geographical patterns in US inventive activity 1977-1998: The "regional inversion" was underestimated. Res. Policy 2017, 46, 1187-1197. [CrossRef]

4. Zhong, Z.; He, L.; Wang, Z. Geographic sources and the structural decomposition of emissions embodied in trade by Chinese megacities: The case of Beijing, Tianjin, Shanghai, and Chongqing. J. Clean. Prod. 2017, 158, 59-72. [CrossRef]

5. Adenle, A.A.; Azadi, H.; Arbiol, J. Global assessment of technological innovation for climate change adaptation and mitigation in developing world. J. Environ. Manag. 2015, 161, 261-275. [CrossRef] [PubMed]

6. Schattman, R.E.; Méndez, V.E.; Merrill, S.C.; Zia, A. Mixed methods approach to understanding farmer and agricultural advisor perceptions of climate change and adaptation in Vermont, United States. Agroecol. Sustain. Food Syst. 2018, 42, 121-148. [CrossRef] 
7. Paik, C.; Shawa, T.W. Altitude and adaptation: A study of geography and ethnic division. Appl. Geogr. $2013,40,212-221$. [CrossRef]

8. Maharjan, A.; de Campos, R.S.; Singh, C.; Das, S.; Srinivas, A.; Bhuiyan, M.R.A.; Ishaq, S.; Umar, M.A.; Dilshad, T.; Shrestha, K.; et al. Migration and household adaptation in climate-sensitive hotspots in South Asia. Curr. Clim. Chang. Rep. 2020, 6, 1-16. [CrossRef]

9. Mitchell, B. Geography and Resource Analysis, 2nd ed.; Longman Scientific and Technical: Harlow, UK, 1989.

10. Jia, X.; Lee, H.F.; Cui, M.; Liu, C.; Zeng, L.; Yue, R.P.H.; Zhao, Y.; Lu, H. Habitat variability and ethnic diversity in northern Tibetan Plateau. Sci. Rep. 2017, 7, 918. [CrossRef]

11. Fum, R.M.; Hodler, R. Natural resources and income inequality: The role of ethnic divisions. Econ. Lett. 2010, 107, 360-363. [CrossRef]

12. Wang, E.; Hu, Z.; Liu, Y.; Zhou, S.; Hao, W. Chinese Cultural Geography; Science Press: Beijing, China, 2014.

13. Guo, R. China Ethnic Statistical Yearbook 2020; Springer Nature: Gewerbestrasse, Switzerland, 2020.

14. Skoggard, I.; Ember, C.R.; Pitek, E.; Jackson, J.C.; Carolus, C. Resource stress predicts changes in religious belief and increases in sharing behavior. Hum. Nat. 2020, 31, 249-271. [CrossRef]

15. Shen, Y. Study on the Spatiotemporal Pattern of Cultural Diversity and Countermeasures of Regional Sustainable Development in Southwest China. Ph.D. Thesis, University of Chinese Academy of Sciences, Beijing, China, 1 June 2018.

16. Sow, P.; Adaawen, S.; Scheffran, J. Migration, social demands and environmental change amongst the Frafra of northern Ghana and the Biali in northern Benin. Sustainability 2014, 6, 375-398. [CrossRef]

17. Hua, X.; Greenhill, S.J.; Cardillo, M.; Schneemann, H.; Bromham, L. The ecological drivers of variation in global language diversity. Nat. Commun. 2019, 10, 2047. [CrossRef] [PubMed]

18. Li, X.C. Regional Historical Geography of China; Peking University Press: Beijing, China, 2004.

19. Demographic Division of National Bureau of Statistics; Economic Division of State Ethnic Affairs Commission. Chinese Ethnic Population Data (Census in 1990); Chinese Statistics Press: Beijing, China, 1994.

20. Demographic and Social Statistics Division of National Bureau of Statistics; Economic Development Division of State Ethnic Affairs Commission. Chinese Ethnic Population Data of Census in 2000; The Ethnic Publishing House: Beijing, China, 2003; Volume 2.

21. Census Office of the State Council; Population and Employment Statistics Division of National Bureau of Statistics. Chinese Ethnic Population Data of Census in 2010; The Ethnic Publishing House: Beijing, China, 2013; Volume 2.

22. Yang, S.M.; Ding, H. The Ethnography of China; Minzu University of China Press: Beijing, China, 2003.

23. Editorial Board of Encyclopedia of China; Editorial Board of the Volume Nation. Encyclopedia of China: Nation, 1st ed.; Encyclopedia of China Publishing House: Beijing, China, 1998.

24. Fu, X.; Shen, Y.; Dong, R.; Deng, H.; Wu, G. Analysis of urbanization based on center-of-gravity movement and characteristics in Songhua River Basin of China and its southern source sub-basin between 1990 and 2010. Chin. Geogr. Sci. 2016, 26, 117-128. [CrossRef]

25. Kozlov, B.И. Ordinary Ethnology Research; Science Press: Moscow, Russia, 1979.

26. Julian, C.G.; Moore, L.G. Human genetic adaptation to high altitude: Evidence from the Andes. Genes 2019, 10, 150. [CrossRef] [PubMed]

27. Storz, J.F.; Scott, G.R. Life ascending: Mechanism and process in physiological adaptation to high-altitude hypoxia. Annu. Rev. Ecol. Evol. Syst. 2019, 50, 503-526. [CrossRef]

28. Chen, W.Y.; Yang, T.; Yang, J.; Qiu, Z.C.; Ding, X.Y.; Wang, Y.H.; Wang, Y.H. Wild plants used by the Lhoba people in Douyu Village, characterized by high mountains and valleys, in southeastern Tibet, China. J. Ethnobiol. Ethnomed. 2021, 17, 46. [CrossRef] [PubMed]

29. Shi, S. Ethnic flows in the Tibetan-Yi corridor throughout history. Int. J. Anthropol. Ethnol. 2018, 2, 2. [CrossRef]

30. Xu, Q.; Wang, J. Recognition of values of traditional villages in southwest China for sustainable development: A case study of Liufang Village. Sustainability 2021, 13, 7569. [CrossRef]

31. Devkota, K.P.; Pasuquin, E.; Elmido-Mabilangan, A.; Dikitanana, R.; Singletona, G.R.; Stuarta, A.M.; Vithoonjitb, D.; Vidiyangkurac, L.; Pustikad, A.B.; Afrianid, R.; et al. Economic and environmental indicators of sustainable rice cultivation: A comparison across intensive irrigated rice cropping systems in six Asian countries. Ecol. Indic. 2019, 105, 199-214. [CrossRef]

32. Wang, H.; Wang, Y. Factors influencing indigenous rice protection in the Yuanyang terraced rice fields of China. J. Resour. Ecol. 2017, 8, 287-295.

33. Wang, H.; Chiou, S. Study on the sustainable development of human settlement space environment in traditional villages. Sustainability 2019, 11, 4186. [CrossRef]

34. Alonso, P.; Blondin, L.; Gladieux, P.; Mahé, F.; Sanguin, H.; Ferdinand, R.; Filloux, D.; Desmarais, E.; Cerqueira, F.; Jin, B.; et al. Heterogeneity of the rice microbial community of the Chinese centuries-old Honghe Hani rice terraces system. Environ. Microbiol. 2020, 22, 3429-3445. [CrossRef] [PubMed]

35. Feng, J.; He, H.; Gao, D.; Li, C. Diversity centers of rice cultivar in Yunnan and their correlation with ecological and cultural factors. J. Resour. Ecol. 2011, 2, 162-167.

36. Song, X.; Li, G.; Vernooy, R.; Song, Y. Community seed banks in China: Achievements, challenges and prospects. Front. Sustain. Food Syst. 2021, 5, 108. [CrossRef] 
37. Ellis, E.C.; Gauthier, N.; Goldewijk, K.K.; Bird, R.B.; Boivin, N.; Díaz, S.; Fuller, D.Q.; Gill, J.L.; Kaplan, J.O.; Kingston, N.; et al. People have shaped most of terrestrial nature for at least 12000 years. Proc. Natl. Acad. Sci. USA 2021, 118, e2023483118. [CrossRef] [PubMed]

38. Nalau, J.; Becken, S.; Schliephack, J.; Parsons, M.; Brown, C.; Mackey, B. The role of indigenous and traditional knowledge in ecosystem-based adaptation: A review of the literature and case studies from the Pacific Islands. Weather. Clim. Soc. 2018, 10, 851-865. [CrossRef]

39. Paul, S.; Das, T.K.; Pharung, R.; Ray, S.; Mridha, N.; Kalita, N.; Ralte, V.; Borthakur, S.; Burman, R.R.; Tripathi, A.K.; et al. Development of an indicator based composite measure to assess livelihood sustainability of shifting cultivation dependent ethnic minorities in the disadvantageous Northeastern region of India. Ecol. Indic. 2020, 110, 105934. [CrossRef]

40. Luo, B.; Liu, B.; Zhang, H.; Zhang, H.; Li, X.; Ma, L.; Wang, Y.; Bai, Y.; Zhang, X.; Li, J.; et al. Wild edible plants collected by Hani from terraced rice paddy agroecosystem in Honghe Prefecture, Yunnan, China. J. Ethnobiol. Ethnomed. 2019, 15, 56. [CrossRef]

41. Mao, S.; Qiu, S.; Li, T.; Tang, M. Rural households' livelihood strategy choice and livelihood diversity of main ethnic minorities in Chongqing, China. Sustainability 2020, 12, 8166. [CrossRef]

42. Li, Y.; Yu, H.; Chen, T.; Cui, H. Livelihood changes and evolution of upland ethnic communities driven by tourism: A case study in Guizhou Province, southwest China. J. Mt. Sci. 2016, 13, 1313-1332. [CrossRef] 